\title{
ÉTICA DE LA RECIPROCIDAD: LA DIMENSIÓN COMUNICATIVA Y AFECTIVA DE LA COOPERACIÓN HUMANA
}

\author{
Patrici Calvo \\ Universitat Jaume I \\ calvop@fis.uji.es
}

\begin{abstract}
RESUMEN / ABSTRACT
Durante las últimas décadas, la capacidad reciprocadora de los seres humanos ha despertado el interés de politólogos, sociólogos y economistas por sus efectos positivos en el desarrollo de los diferentes ámbitos de actividad humana. Se trata de un comportamiento que permite la emergencia de diversas formas de cooperación entre dos o más personas para la satisfacción de objetivos compartidos y altamente beneficiosos para todas las partes en relación. Sin embargo, tal y como muestran diversos estudios, tras la emergencia y potenciación de la reciprocidad subyace una dimensión ética y emocional. En este sentido, el objetivo de este estudio es proponer una posible reconstrucción de las condiciones de posibilidad de la reciprocidad.
\end{abstract}

Palabras ClaVe: ética, reciprocidad, cooperación, comunicación, afectos.

\section{ETHICS OF RECIPROCITY: THE COMMUNICATIVE AND AFFECTIVE DIMENSION OF HUMAN COOPERATION}

During the last decades, the reciprocating capacity of human beings has aroused the interest of political scientists, sociologists and economists for their positive effects on the development of different areas of human activity. It is a behavior that allows the emergence of various forms of cooperation between two or more people for the satisfaction of shared objectives and highly beneficial for all parties in relation. However, as several studies show, an ethical and emotional dimension underlies the emergence and enhancement of reciprocity. In this sense, the objective of this study is to propose a possible reconstruction of the conditions of possibility of reciprocity.

KEYWORDS: Ethics, Reciprocity, Cooperation, Communication, affections.

RA La reciprocidad ha sido un tema recurrente para la antropología social. En Stone Age Economy (1972), Marshall Sahlins recopiló, desarrolló y sistematizó buena parte del conocimiento generado por la disciplina durante décadas a través de los trabajos de Marcel Mauss, Bronislaw Malinowski, Karl Polanyi, Raymond Firth, Edward Evan Evans-Pritchard, Elman R. Service, Marvin Harris y Richard B. Lee, entre otros. A través de estos autores, Sahlins propuso la existencia de diferentes tipos de reciprocidades, cada cual con unas características y capacidades diferentes, y que 
éstas han desempeñado un papel nuclear en la subsistencia y evolución de las sociedades primitivas a lo largo de la historia. Como argumenta Sahlins,

Los tipos reales de reciprocidad son muchos en una sociedad primitiva, aislada en el mundo primitivo tomado como un todo. Los "movimientos viceversa" pueden incluir el reparto y el contrarreparto de comida sin preparar, la hospitalidad informal, los intercambios ceremoniosos afines, la transferencia que sella un acuerdo de paz, los préstamos y devoluciones, la compensación por servicios ceremoniales o especializados, la disputa interpersonal, etc. (1972).

A partir de ahí, Sahlins propone tres grandes tipologías sobre las distintas formas de reciprocidad existentes en las sociedades antiguas: generalizada, equilibrada y negativa.

a) La reciprocidad generalizada tiene que ver con aquellas transacciones entre agentes con intereses económicos y sociales afines que pueden ser consideradas altruistas, en tanto y cuanto el tiempo de respuesta y la retribución esperada no queda definido previamente (Sahlins 1972: 212).

b) La reciprocidad equilibrada agrupa aquellos intercambios directos, inmediatos y equivalentes que se dan entre agentes con intereses económicos y sociales distintos que pueden ser considerados autointeresadas, en tanto que "(...) consisten en la entrega habitual del equivalente de la cosa recibida sin demoras. (...) es decir, el intercambio simultáneo de las mismas clases de bienes en las mismas cantidades" (Sahlins 1972: 213).

c) La reciprocidad negativa concentra aquellos intercambios directos e inmediatos entre agentes con intereses contrapuestos que pueden ser considerados egoístas, en tanto que buscan maximizar el beneficio a expensas del otro a través de obtener impunemente un mayor rendimiento de la transacción Sahlins 1972: 213-14).

Para Sahlins, los comportamientos recíprocos que componen las diferentes tipologías han acompañado las sociedades durante miles de años. Éstos emergieron y se desarrollaron como forma de posibilitar relaciones de intercambio social y económico internas y externas; es decir, tanto entre $n$-individuos de una misma comunidad como entre $n$-comunidades y $n$-individuos de sociedades distintas a través de las cuales sea posible satisfacer necesidades que mejoren sus expectativas de subsistencia y proyectos de vida buena. De esta forma, a través de estas y otras ideas, Sahlins presenta un origen y fundamento de la cooperación humana alejado de los estereotipos y mitos que subyacen a los discursos convencionales (Sahlins 1972: 252). Por ejemplo, la cooperación basada en la racionalidad instrumental y homogénea -idea promovida por la teoría económica tradicional-y la cooperación basada en el altruismo puro -idea defendida por ciertos movimientos solidarios- representan dos de las diversas opciones disponibles para los participantes, pero ni son las únicas ni tienen por qué ser las más utilizada según el contexto. 
Además, la reciprocidad es un comportamiento que, paradójicamente, logra aunar y complementar el autointerés y el altruismo para lograr un objetivo común de forma más eficiente, eficaz y, sobre todo, justa. Como sugiere Sahlins, de la reciprocidad vinculada con la emergencia y subsistencia de la relacionalidad dentro de las diferentes sociedades antiguas, incluso aquellas relacionadas con la economía, subyacen aspectos éticos. Los habitantes actuales de las islas Trobriand, por ejemplo, disponen de un término específico para la ética económica: pokala (Sahlins 1972: 225), muy relacionada con el don, la reciprocidad y las expectativas recíprocas de comportamiento. La emergencia de la economía, por tanto, parece intrínsecamente ligada tanto a una reciprocidad ética como a una ética de la reciprocidad; es decir, tanto a un comportamiento reciproco del cual subyacen aspectos de justicia como a una reflexión sobre la validez moral de los comportamientos recíprocos.

El objetivo del presente trabajo será profundizar en la dimensión ética y afectiva de la reciprocidad. Para ello, en un primer momento se mostrará, mediante el análisis de diferentes mitos, la relación intrínseca que existe entre la reciprocidad y la emergencia y pervivencia de la cooperación. En un segundo momento, se abordará el papel que desempeña la reciprocidad en los distintos ámbitos de actividad humana, así como algunas de sus diferentes formas. Finalmente, se propondrá una reconstrucción dialógica y emocional de las condiciones de posibilidad de la reciprocidad, un modelo que tiene en cuenta tanto los afectos como el necesario momento ético-crítico que requiere todo comportamiento que desee estar a la altura de lo observado, deseado y exigible por una sociedad cordial.

\section{Cinco mitos sobre la cooperación humana: una crítica desde la reciprocidad}

La cooperación, del latín tardío cooperatio, -ōnis, tiene que ver con la “(...) acción y efecto de cooperar", y el acto de cooperar, del latín tardío cooperāri, con "(...) obrar conjuntamente con otro u otros para la consecución de un fin común" (DLE 2018). La cooperación, por consiguiente, es una acción llevada a cabo por al menos dos personas, que emerge y se desarrolla para satisfacer objetivos compartidos y comúnmente beneficiosos para las partes en relación no necesariamente vinculados con el autointerés o el altruismo.

La cooperación, tal y como sugieren diferentes estudios, guarda una estrecha relación con la reciprocidad, la reputación y la confianza (Ostrom 2003). Estos tres valores constituyen la estructura axiológica de la cooperación, pues, como sugiere Ostrom, comportarse recíprocamente permite generar y/o potenciar indirectamente nuestra reputación individual o colectiva, la cual posibilita la generación de expectativas razonables sobre la confiabilidad de las personas o grupos vinculados o vinculables, y estas facilitan la posible concreción de proyectos comunes y su proyección fáctica gracias a la cooperación.

Además, para su implementación práctica, la cooperación exige emociones prosociales y acciones comunicativas tendentes al entendimiento sobre diferentes cosas de este mundo. En tanto que ésta es una conducta prosocial, el sentir y emocionarse 
por los demás es una condición de posibilidad de su emergencia (Ostrom 2004); y en tanto que la cooperación necesita coordinar la acción para poderse llevar a cabo, la satisfacción de ciertas pretensiones de validez comunicativas y emocionales son también necesarias para ello (Calvo 2018).

Sin embargo, uno de los grandes problemas actuales para la emergencia, implementación y desarrollo de la cooperación, es su vinculación con ciertos mitos que, dependiendo del punto de vista del que se parta -el autointerés o el altruismo-, ralentizan o limitan tanto su proyección práctica como su desarrollo teórico. Entre estos, cabe destacar cinco por su influencia en diferentes campos de actividad:

- La cooperación es una ficción. Ni existe, ni puede existir, puesto que el ser humano es egoísta por naturaleza, y, por tanto, individualista y autointeresado en cualquier ámbito de actuación ${ }^{1}$.

Esta afirmación, muy asentada en ámbitos como el económico ${ }^{2}$, carece de fundamento. Las neurociencias han demostrado que estamos biológicamente programados para colaborar y cuidar de nuestros semejantes, incluso en aquellos casos cuando la cooperación supone una desventaja adaptativa desde el punto de vista evolutivo. Además, estudios neurocientíficos sobre las bases cerebrales de la reciprocidad sugieren que el cerebro humano dispone tanto de potenciadores químicos de la cooperación, que se activan cuando se detectan potenciales cooperadores, como inhibidores de ésta, que se activan solo cuando se descubren free-riders (Suzuki et al. 2011).

- La cooperación es un pacto de intereses entre seres egoístas donde cada una de las partes en relación busca maximizar su propio bienestar personal. Las personas autointeresadas lo utilizan para maximizar el beneficio extrínseco (dinero, posesiones materiales, etc.), y las personas solidarias para maximizar los beneficios intrínseco (autoestima, reputación, bienestar, prestigio, etc.) ${ }^{3}$.

En esta afirmación existen, al menos, dos errores importantes. Por un lado, se confunde el fin interno con los bienes externos. Una cosa es el fin que da sentido a una acción, que en el caso de la cooperación es la satisfacción de objetivos comúnmente compartidos, valorados y beneficiosos (no solo económicamente) por todos los participantes, y otra cosa muy distinta son las condiciones que lo hacen posible, que en el caso de la cooperación puede ser la financiación, el voluntariado, el beneficio económico, el prestigio, la mejora continuada de procesos y productos, los bienes intrínsecos, etc., según el ámbito de aplicación y el tipo de objetivo perseguido. La confusión entre ambos niveles pervierte el fin que da sentido a la cooperación y genera corrupción y mala praxis. Por otro lado, los seres egoístas utilizan equilibrios para relacionarse, pero los equilibrios no tienen nada que ver con la cooperación. En primer lugar, porque la base cerebral de ambos es totalmente distinta y dicotómica, tal y como han mostrado diferentes estudios neuroeconómicos

Para algunos estudios en este sentido, Olson (1965) y Hardin (1968).

En el ámbito económico, esta idea fue incluso axiomatizada por Kennetth Arrow (1950, 1951), a través de los supuestos de monitonicidad, codicia e insaciabilidad.

Para un estudio crítico sobre estas ideas, Zamagni (2009). 
(McCabe et al. 2001; Van den Bos et al. 2009; Suzuki et al. 2011; Ohtsuki et al. 2009) y neuropsicológicos (Sturm 2017; Orlitzky 2016; Schwartz 2016; Dedeke 2013; Woiceshyn 2011, and Kahane y Shackel 2010). Y, en segundo lugar, porque los equilibrios ofrecen soluciones con beneficios subóptimos, mientras que la cooperación permite la búsqueda de un óptimo resultado para todas las partes en relación (Ostrom, 2000, 2004, Bowles y Gintis, 2011).

- La cooperación es una acción solidaría dirigida hacia los más vulnerables de la sociedad. Por tanto, no tiene nada que ver con actividades como la economía o la política ${ }^{4}$.

La cooperación se encuentra en la base de la buena salud de cualquier actividad humana, con independencia de cuál sea su objetivo principal. Ninguna actividad puede subsistir mucho tiempo sin cooperación. Por ejemplo, un hospital funciona mediante procesos cooperativos donde participan profesionales de diferentes ámbitos (medicina, enfermería, administración, voluntariado, etc.); una empresa necesita de la cooperación de sus diferentes stakeholders para poder desarrollar correctamente su actividad; y una organización política tiene que conseguir la colaboración comprometida de sus grupos objetivos para consolidarse, legitimarse y subsistir (González-Esteban 2001, 2013; García-Marzá 2004, 2005; Feenstra et al. 2017).

- La cooperación es una acción solidaría y altruista dirigida hacia personas con pocos recursos. Por tanto, no podemos esperar nada de ellas 5 .

Esta idea constituye uno de los grandes mantras de la cooperación en todas sus dimensiones. Todo ser humano tiene mucho que aportar, ya sea en cantidad o en calidad. El problema es que se confunden las capacidades humanas con los recursos materiales. Que las personas no dispongan de recursos económicos para poder llevar a cabo sus planes de vida buena; cuidarse, alimentarse y subsistir; disponer de servicios, tecnología y/o medicamentos, etc., no significa que no puedan ayudar en el acto cooperativo y/o responder adecuadamente de la ayuda percibida -en cantidad o calidad- a corto, medio o largo plazo. El dar sin esperar y recibir sin actuar es un grave problema, puesto que socaba las bases de la cooperación y produce hastío, vergüenza, culpa, pena, falta de autoestima y/o resentimiento en quienes son objeto de la ayuda (Senneth 2003). No se puede excluir al vulnerable de una acción cooperativa donde él es el foco de atención. Éste puede aportar mucho en el proceso y de innumerables formas.

- La cooperación es una acción solidaria y altruista, y, por tanto, lo que importa es el fin, no los medios. Si nos preocupasen los medios, se convertiría en una acción estratégica que puede instrumentalizar incluso a las personas receptoras ${ }^{6}$.

$4 \quad$ Esta es una idea que también subyace al trabajo de Olson sobre la imposibilidad de la acción colectiva en ámbitos como la economía (1965).

Para un estudio crítico sobre estas ideas, Zamagni (2009).

Esta es una idea muy extendida entre organizaciones del tercer sector. De ahí los continuos casos de organizaciones que aceptan financiación de cualquier tipo, sea o no lícita, sea o no moralmente aceptable, o que realizan prácticas contrarias a su propia filosofía. Por ejemplo, el uso de mano de obra precaria para conseguir financiación: "Las ONG han echado el resto en comunicación y se han lanzado a cerrar campañas muy agresivas a nivel de calle 
Varias cuestiones al respecto. En primer lugar, esta idea reduce la cooperación a aquellas acciones que estén cimentadas sobre la lógica de la solidaridad. Sin embargo, tal y como se ha argumentado, la cooperación es necesaria en todo ámbito de actividad humana, incluso en aquellos espacios donde la lógica dominante no es la solidaridad, sino el lucro, el cuidado o la salud, por citar algunos. En segundo lugar, centrándose en acciones cooperativas vinculadas con la solidaridad, tan importante es el fin como los medios para alcanzarlos. El fin es lo que le da sentido a la acción, su justificación de por qué existe o debería existir. Pero sin recursos materiales (financiación, medios de transporte, alimentos, etc.), motivacionales (prestigio, lucro, autoestima, bienestar, placer, etc.) y relacionales (confianza, reconocimiento, reciprocidad, reputación, respeto, etc.) no se podría materializar en la práctica. En tercer lugar, si solo miramos el fin, podemos acabar justificando el uso de medios ilícitos o inmorales para conseguirlos. Para una organización que lleve a cabo acciones para paliar los efectos de las minas terrestres antipersonas, pierde todo sentido cunado acepta la financiación de empresas armamentísticas, dedicadas a la fabricación de estos u otros artilugios de muerte, por dar algún ejemplo.

Estos y otros mitos constituyen un mantra para la cooperación en todas sus dimensiones que ralentizan, limitan o lastran su potencialidad, y, sobre todo, evidencian un desconocimiento sobre sus fundamentos y estructura. Especialmente, sobre el papel fundamental que juega la reciprocidad en su emergencia, implementación y desarrollo en el ámbito práctico. Se trata de una competencia capaz de aunar conductas tan dispares como el autointerés y el altruismo; que exige y mejora recursos motivacionales como las emociones prosociales; que potencia y nutre de bienes relacionales como la confianza o la reputación; y que tiene una dimensión tanto estratégica como afectiva y comunicativa

\section{Enfoques de reciprocidad: de la supervivencia a la cordialidad}

Según señala Richard Gould en "To have and not to have: the ecology of sharing among hunter-gatherers" (1982), la reciprocidad surgió hace miles de años como una medida adaptativa frente a la incertidumbre generada por la constante fluctuación de los alimentos disponibles, y que cuanto mayor es el nivel de riesgo en una sociedad, más capacidad de compartir demuestra ésta y sus ciudadanos. Concretando esta idea, Michael Tomasello señala que la cooperación humana surgió hace alrededor de 500.000 años en un momento crítico para la supervivencia del grupo (Mediavilla, 22 de octubre de 2015). Los homínidos comprendieron que a través de la cooperación se obtenía una ventaja competitiva desde el punto de vista evolutivo, especialmente en momentos de penuria, y ésta era posible gracias a cuatro cuestiones básicas intrínsecamente relacionadas con la posibilidad y emergencia de la reciprocidad: la competencia y capacidad reciprocadora de los seres humanos; las emociones positivas que generan

con las que captar nuevos socios. En ocasiones, utilizando trabajadores precarios con ese fin, tal y como ha denunciado entre otros el sindicato CCOO" (Gutiérrez 2018). 
los comportamientos recíprocos, mucho mayor hacia la gente del grupo; la reacción que produce la violación de las expectativas recíprocas de comportamiento; y el reparto justo de los beneficios obtenidos por la relación, que depende de criterios como el grado de esfuerzo o responsabilidad de cada uno de los participantes.

A partir de ese momento, los seres humanos han ido concretando y desarrollando en la práctica distintos comportamientos recíprocos según el contexto, las circunstancias, los objetivos y los intereses implicados en cada caso concreto para establecer procesos cooperativos tendentes a la satisfacción de objetivos comúnmente compartidos. Destacan al respecto el egoísmo recíproco, el altruismo recíproco, la reciprocidad indirecta, la reciprocidad social, la reciprocidad fuerte, la reciprocidad incondicional, la reciprocidad transitiva, la reciprocidad inclusiva, la reciprocidad institucional, y la reciprocidad cordial (Calvo 2018).

El egoísmo recíproco es aquel comportamiento que busca producir buena reputación como colaboradores para, llegado un caso extremo de necesidad, ser incluidos en aquellas redes de relacionalidad que ofrecen mayores perspectivas de supervivencia, ya sea evolutiva, económica y/o políticamente hablando. Este tipo de comportamiento recíproco, descubierto y descrito por Robert Frank en la década de los 80 del siglo pasado (1988), encaja perfectamente con el proceso que, según Tomasello, dio pie a la emergencia de la cooperación humana, y que demandó la existencia de una dimensión afectiva y moral tanto de la reciprocidad como de la cooperación subyacente.

El altruismo recíproco es un comportamiento amable donde se asumen los costes derivados de ayudar a otros siempre y cuando existan expectativas razonables de un retorno futuro en caso de necesidad. El objetivo de la acción no es granjearse buena reputación, sino minimizar la incertidumbre mediante la generación de una especie de seguro de cobertura frente a riesgos futuros ya sea dentro o fuera del grupo. Este comportamiento recíproco, propuesto por Robert Trivers (1971) y James W. Friedman (1971) en la década de los 70 del siglo pasado, fue considerado por Robert Axelrod (1984) como la estrategia que mejores resultados ha demostrado en materia de política internacional.

La reciprocidad indirecta es una cadena invertida de comportamientos recíprocos consistente en ayudar $u$ ofrecer algo a quienes han demostrado una actitud similar con otras personas. El objetivo no es lograr una respuesta comportamental de la persona que recibe la ayuda, ya sea en cantidad o calidad, sino forjarse una buena reputación como reciprocador para ser considerado por los demás como alguien digno de ser ayudado. Este comportamiento recíproco, propuesto y formalizado por Robert Sugden (1986) y Richard Alexander (1987) en la década de los 80 del siglo pasado, pudo emerger como una forma eficaz de detectar free-riders y evitar los efectos corrosivos que estos tienen sobre la cooperación. La acción indirecta exige que las partes vinculables deban demostrar previamente y con acciones concretas su predisposición a colaborar con sus semejantes. Así, primero se tiene que demostrar que se es capaz dar, y luego, gracias a la buena reputación que se ha labrado, se recibe de otros. Quienes no ofrecen algo no pueden granjearse buena reputación, $y$, por tanto, quedan fuera de las redes de cooperación. 
La reciprocidad social es un comportamiento recíproco que, apoyándose en la información indirecta procedente de redes interpersonales de información y participación para germinar e implementarse (capital social), busca obtener un resultado óptimo para todas las partes en relación a través de procesos colaborativos de larga duración. Propuesto por Elinor Ostrom $(1990,2003)$ durante la década de los 90 del siglo pasado como elemento clave en la gestión de los bienes comunes, se trata de una reciprocidad directa-se da con la intención de recibir- que, pensada como capital social, desplaza los equilibrios para maximizar el beneficio de forma óptima a través de acciones colectivas. Aquí, la base de la buena reputación de las partes vinculables no es la acción y observación directa sobre su mutua capacidad de reciprocar, como en el caso de la reciprocidad indirecta, sino la posibilidad de consultar la información disponible sobre todos ellos gracias a redes sociales de información y comunicación.

La reciprocidad fuerte es aquel comportamiento recíproco que tiende a colaborar con quienes actúan de forma similar y a castigar comportamientos no respetuosos con las normas sociales o morales implicadas, aun cuando tal conducta conlleve un coste personal elevado. Este tipo de reciprocidad, descrito y estudiado por Samuel Bowles y Herbert Gintis $(1998,2011)$, entre otros, durante los años 90 del siglo pasado, constituye una forma de colaboración que se ha mantenido estable e inalterable a lo largo de al menos 150.000 años. Apoyada en ciertas capacidades cognitivas, lingüísticas y ontogenéticas sólo accesibles para los seres humanos, la reciprocidad fuerte tiene la peculiaridad de castigar duramente a quienes no cumplen con las expectativas recíprocas de comportamiento con independencia de cuál sea el coste. Este castigo altruista ha servido como mecanismo disuasorio, preventivo y controlador de los free-rider para lograr mantener en los grupos de $n$-personas una colaboración robusta como elemento de diferenciación y ventaja competitiva desde un punto de vista evolutivo.

La reciprocidad incondicional es aquel comportamiento recíproco que busca satisfacer necesidades humanas en otras personas para producir un aumento exponencial del bienestar intrínseco en el procurador. Descrito y desarrollado por Luigino Bruni (2006) durante la primera década del siglo XXI, se trata de una acción muy cercana al altruismo, cuya principal característica es su incondicionalidad extrínseca gracias a los beneficios psicológicos que genera en la persona o grupo del que parte la colaboración. Es decir, toda ayuda espera una respuesta comportamental de quien la recibe, puesto que el acto recíproco no se materializa en ausencia de respuesta. Sin embargo, la peculiaridad de este comportamiento es que la inacción del receptor no condiciona la continuidad de la relación, puesto que los bienes intrínsecos que produce-autoestima, bienestar, satisfacción personal, placer, etc.- compensan a corto, medio y largo plazo la falta de respuesta del receptor de la ayuda.

La reciprocidad transitiva es aquel comportamiento recíproco que, orientado hacia el empoderamiento de las partes en relación, busca una respuesta comportamental del receptor fruto de la ayuda percibida, ya sea en cantidad o en calidad, ya sea hacia el que le ofreció su colaboración o hacia otras personas. Descrito y desarrollado por Stefano Zamagni durante la década de los 90 del siglo veinte a través de su propuesta de economía civil, su objetivo último es el establecimiento de relaciones estables capaces de producir bienes relacionales autorrealizativos para todas las partes implicadas. Se 
trata de una especie de cadena transitiva de comportamientos recíprocos; es decir, el que ofrece algo a alguien espera que éste utilice la ayuda para empoderarse y, de ese modo, sea capaz o bien devolver la ayuda, en cantidad o en calidad, o bien ayudar a otras personas a empoderarse y continuar con la cadena. Lo importante para el que ofrece no es el retorno equivalente de la ayuda prestada, sino la relación que se puede generar entre ambos y que produce bienes autorrealizativos como la amistad.

La reciprocidad inclusiva es aquel comportamiento recíproco de carácter transitivo que pretende ayudar con el fin de empoderar al otro, esperando una actitud activa de quien la recibe. Propuesta por Adam Smith en el siglo XVIII (1776) y recuperada y trabajada en la segunda década del siglo XXI (Calvo 2018), se trata de un comportamiento recíproco sustentado en la solidaridad, cuyo principal objetivo es servir como mecanismo de inclusión en el mercado de las personas más desfavorecidas e, indirectamente, como instrumento de desarrollo económico y social. Lo que pretende Adam Smith con su propuesta, es tanto advertir que el mercado florece y desarrolla gracias a los comportamientos recíprocos, y no por los egoístas o altruistas, como mostrar lo infructuoso que resulta para la economía y la sociedad tanto el acto de dar sin esperar como de recibir sin actuar. La benevolencia es muy positiva, en tanto en cuanto se utilice en el marco de relaciones reguladas por la lógica de la reciprocidad ${ }^{7}$.

La reciprocidad institucional es aquel comportamiento recíproco que asume los costes derivados de ayudar a otras personas a cambio de que ello redunde beneficiosamente en el desarrollo y enriquecimiento de una institución concreta de la que se forma y se siente parte. Propuesta y trabajada durante la segunda mitad del siglo XXI (Calvo 2018), se trata de una acción colaborativa con resultados indirectos. Aquí, el objetivo principal para establecer o mantener una colaboración con otras personas no es obtener un beneficio intrínseco o extrínseco para las partes vinculadas o vinculables, en calidad o cantidad, sino mejorar la sostenibilidad de la institución a la que se pertenece, no necesariamente contractualmente, y con la que se está emocional y/o comprometidamente vinculado.

La reciprocidad cordial es aquel comportamiento bidireccional donde los seres en relación reconocen mutuamente su dignidad y vincularidad y sus capacidades comunicativas y emotivas para entenderse sobre distintas cosas del mundo y comprometerse a cumplir con el marco de actuación y el desempeño de objetivos particulares, colectivos o universalizables en cualquier ámbito de actividad humana. Propuesto y trabajado a lo largo de la segunda década de siglo XXI (Calvo 2018) a partir de los trabajos de Adela Cortina $(2007,2010,2017)$, se trata del acto que subyace al reconocimiento mutuo y

7 En sus trabajos, Adam Smith sugiere que la reciprocidad y no el egoísmo o el altruismo es uno de los factores decisivos en el desarrollo económico, social y humano. Para ello propone dos tipos de reciprocidad, uno directo basado en el intercambio de equivalentes, la reputación y el acuerdo, cuyo objetivo es el correcto funcionamiento del mercado, y otro transitivo basado en la compasión, la virtud y la participación, cuyo objetivo es facilitar el acceso de los excluidos al mercado. 
que constituye la base de cualquier acto recíproco que desee estar a la altura de aquello que el actual momento histórico considera deseable y exige. Es decir, cualquier proceso colaborativo tendente a la satisfacción óptima de objetivos mutuamente compartidos que pretenda emerger y desarrollarse correctamente, dentro del marco de mínimos de justicia compartidos, debe forjarse desde el reconocimiento cordial de las competencias y capacidades comunicativas y afectivas de las partes vinculadas o vinculables.

De estas diversas formas de reciprocidad, que permiten establecer diferentes procesos colaborativos entre los seres humanos para buscar objetivos particulares, colectivos y generales, se vislumbran varias cuestiones importantes sobre la cooperación humana. Entre otras cosas, que la cooperación es un comportamiento intrínsecamente ligado con la reciprocidad, que, según la forma utilizada, permite compatibilizar en mayor o menor medida conductas aparentemente irreconciliables, como el autointerés y el altruismo; que el acto reciproco mantiene una estructura comportamental basada en el ofrecimiento, la aceptación y la respuesta [Figura 1]; y que tras el nivel de la aceptación subyace una dimensión comunicativa y afectiva que es condición de posibilidad de la emergencia, subsistencia y desarrollo del acto recíproco y, por ende, de la cooperación humana.

\section{La estructura interna de la reciprocidad: ofrecer, aceptar, responder}

En el prólogo de la edición española de El gobierno de los comunes. La evolución de las instituciones de acción colectiva (2000), Elinor Ostrom afirma que la reciprocidad es un conjunto de estrategias que los seres humanos hacen servir para satisfacer objetivos comunes a través de la cooperación. Qué reciprocidad y cómo y cuándo se utiliza, dependerá del contexto en el que se aplique, de los móviles de la acción, de las emociones prosociales implicadas y del nivel de reputación directa o indirecta y confianza alcanzado entre las partes vinculadas o vinculables. Para Ostrom, por consiguiente, la reciprocidad es un mecanismo que estimula y permite la emergencia y mantenimiento de relaciones cooperativas entre humanos tendentes a la satisfacción de objetivos compartidos.

No obstante, diferentes experimentos de laboratorio con juegos de estrategia dentro de la teoría de juegos tradicional, evolutiva y neuronal a lo largo de las últimas décadas han mostrado lo que, la filosofía primero y la antropología después, llevan siglos advirtiendo: tras las distintas formas de reciprocidad subyace una dimensión estratégica y afectiva, como argumenta Ostrom, pero también moral, como argumenta Sahlins. Las personas no solo están biológicamente predispuestas a cooperar con y cuidar de sus semejantes. Éstas también son capaces de sentir y emocionarse por uno mismo y por los demás y de dejarse guiar por aquello que consideran justo o correcto, aun cuando ello suponga un alto coste para sí mismo (Cortina 2010).

En este sentido, tras la reconstrucción de las condiciones de posibilidad de la reciprocidad subyacen ciertas pretensiones de validez y expectativas de afectividad que deben ser satisfechas por las partes relacionalmente vinculadas o vinculables para que ésta emerja, se implemente y se desarrolle correctamente. Es decir, la posibilidad 
de la reciprocidad tiene una dimensión estratégica, pero también moral y emocional que deben ser abordadas y gestionadas debidamente para que emerja la cooperación entre dos o más personas.

Tradicionalmente, tal y como afirman diferentes estudios (Bowles y Gintis 2011; Ostrom 2003, Zamagni 2006; Bruni 2006), la estructura del acto recíproco se compone de dos momentos. El primero, dar, proponer u ofrecer algo; el segundo, responder de ese algo. Sin embargo, no en pocas ocasiones alguna de las partes desestima la ayuda, propuesta u oferta de colaboración, $y$, por consiguiente, el acto no se concreta y la colaboración no se establece. Tras este hecho subyacen varias cuestiones a tener en cuenta.

En primer lugar, que existe un tercer momento, el de aceptar, que es intermedio entre el ofrecer y el responder y que actúa de filtro bidireccional para el establecimiento y la continuidad de la relación. Cuando alguien ayuda, propone $u$ ofrece algo a alguien, el receptor tiene que aceptar el ofrecimiento y, posteriormente responder adecuadamente, ya sea en cantidad o calidad, ya sea hacia el proponedor o hacia otra u otras personas. Pero para que el acto recíproco se dé, también es necesario que la persona que ofreció la ayuda, propuesto $u$ oferta acepte la respuesta dada por el receptor de la misma. Y así sucesivamente. Por tanto, el nivel de la aceptación actúa como filtro en cada nuevo movimiento de las partes vinculadas o vinculables, controlando tanto el establecimiento del proceso cooperativo como la continuidad y perdurabilidad del mismo.

En segundo lugar, que este nivel intermedio, el de la aceptación de la ayuda, propuesta u oferta, se halle mediado por una dimensión comunicativa, cuya lógica es el entendimiento o acuerdo intersubjetivo de todos los afectados sobre las consecuencias que se deriven de su aceptación o rechazo, y su mecanismo es el establecimiento de un proceso de diálogo con ciertas reglas argumentativas y principios morales que velan por la inclusión de todos los afectados presentes y futuros, el reconocimiento de todos los intereses en juego, y la existencia de ciertas garantías de igualdad, simetría y no coerción tal y como propuso Jürgen Habermas en su teoría de la acción comunicativa (1981).

En tercer lugar, y siguiendo la reconstrucción de las condiciones de posibilidad del entendimiento sobre diferentes cosas de este mundo realizada por Habermas (1981), que la dimensión comunicativa que subyace al nivel de la aceptación de la ayuda, propuesta $\mathrm{u}$ oferta debe cumplir con tres pretensiones de validez: veracidad, verdad y justicia. Por un lado, el receptor entiende que la ayuda, propuesta $u$ oferta que recibe es sincera. Si tiene dudas respecto de las intenciones del proponedor, el receptor no aceptará, el acto de reciprocar no se materializará y el proceso colaborativo no dará comienzo. Por otro lado, el receptor entiende que la ayuda, propuesta u oferta que recibe es posible y realizable. Si tiene dudas sobre sus posibilidades, cree que es inviable o que se trata de una quimera o utopía, el receptor desestimará el ofrecimiento, y la reciprocidad y cooperación no se realizará. Aquello que se proponga, por tanto, debe mantener una correspondencia adecuada con la realidad. Finalmente, el receptor entiende que la ayuda, propuesta u oferta que recibe cumple con los mínimos de justicia exigibles para todo ser humano. Si duda de su legitimidad moral, como una posible violación de los Derechos Humanos, también puede generar que se deseche el ofrecimiento, y la reciprocidad y cooperación no se materialice. Aquello que se proponga, debe ser moralmente válido. 
En cuarto lugar, tal y como propuso Habermas en su teoría de la acción comunicativa (1981), que la ruptura de una de las pretensiones de validez, especialmente las de verdad y justicia, no significa necesariamente la imposibilidad de llegar al entendimiento entre las partes para coordinar la acción en pos de objetivos comúnmente compartidos. A través del diálogo, es posible restablecer aquellas pretensiones de validez rotas o cuyo cumplimiento despierta dudas o suspicacias razonables. Como argumenta Ortega Esquembre, cuando “(...) estas certezas orientadoras de la praxis se vuelven problemáticas adquieren la forma de un enunciado hipotético cuya validez hay que defender, o criticar, en el discurso racional" (Ortega-Esquembre 2016). Se trataría del establecimiento de un proceso comunicativo sustentado sobre un principio moral procedimental [D]-solo pueden pretender ser válidas aquellas normas, acciones o decisiones que dentro de un discurso práctico con ciertas reglas y principios puedan suscitar la aprobación de todos los afectados- $\mathrm{y}$ un principio de universalización [U] -toda norma, acción o decisión que pretenda ser válida debe cumplir con la condición de que sus afectos y consecuencias previsiblemente derivadas puedan ser aceptadas por todos los afectados- cuya única coacción aceptable es la que suscita el mejor argumento. Estos dos principios obligan a cumplir con el criterio de inclusión - todos los afectados presentes y futuros deben poder participar en los procesos de diálogo donde se discuten aquellas normas, acciones o decisiones que le afecten o competen-, igualdad-todos los participantes del proceso deben poder argumentar en igualdad de condiciones (acceso a la información, ausencia de presiones, mismo tiempo para hablar, etc.)-, y reciprocidad -todos los intereses de los participantes deben ser considerados por igual y estar abiertos a revisión crítica por parte de los demás-(García-Marzá 1992). A través de este proceso dialógico es posible intentar entenderse sobre diferentes cosas de este mundo para coordinar la acción y buscar la satisfacción de proyectos comunes.

En cuarto lugar, que el nivel intermedio de la aceptación de la ayuda, propuesta u oferta también se halla mediado por una dimensión emotiva, la cual debe cumplir con tres expectativas de afectividad: interés, preferencia y consecuencias. Por un lado, que al receptor le interesa el ofrecimiento. Por bueno que este sea, si al receptor no está interesado en la ayuda, propuesta u oferta, la desestimará y el acto recíproco no se llevará a cabo. Por otro lado, que al receptor le parezca que el ofrecimiento entra dentro de sus preferencias presentes o futuras. Puede que la ayuda, propuesta $u$ oferta tenga interés para el receptor, pero tal vez no constituye una preferencia en este momento. De ser así, tampoco aceptará el ofrecimiento y el acto recíproco no se llevará a cabo. Por beneficioso que este pueda ser para las partes en relación, si al receptor no está interesado en la ayuda, propuesta u oferta, la desestimará y el acto recíproco no se concretará en la práctica. Finalmente, que el receptor acepte las consecuencias derivadas de su aceptación. Puede que la ayuda, propuesta u oferta sea del interés del receptor, que entre dentro de sus preferencias, pero tal vez no éste dispuesto a aceptar sus efectos. De ese modo, tampoco en este caso se materializaría la reciprocidad y la colaboración no sería posible.

En definitiva, la cooperación emerge y potencia gracias a la reciprocidad, un comportamiento con múltiples formas cuya estructura interna muestra un anclaje comunicativo y afectivo y en la cual subyace una dimensión ética y emotiva que es condición de posibilidad de su concreción, desarrollo y subsistencia. 


\section{Referencias bibliográficas}

Alexander, Richard (1987), The Biology of Moral Systems. New York: Aldine.

Arrow, Kenneth J. (1950), “A Difficulty in the Concept of Social Welfare”, Journal of Political Economy 58 (4): 328-346. Sons.

(1951), Social choice and individual values. New York: John Wiley \&

Axelrod, Robert (1984), The evolution of cooperation. New York: Basic Books.

Bowles, Samuel y Herbert Gintis (1998), "Is equality Passé? Homo reciprocans and the future of egalitarian politics", Boston Review 23 (6): 1-27.

(2011), A Cooperative Species. Human Reciprocity and Its Evolution. Princeton: Princeton University Press.

Bruni, Luigino (2006), Il prezzo della gratuità. Roma: Città Nuova.

Calvo, Patrici (2018), The Cordial Economy - Ethics, Recognition and Reciprocity. Cham: Springer.

Cortina, Adela (2007), Ética de la razón cordial. Educar en la ciudadanía en el siglo XXI. Oviedo: Nobel.

(2010), Justicia Cordial. Madrid: Trotta.

(2017), Aporofobia, el rechazo al pobre. Un desafio para la democracia. Barcelona: Paidós Ibérica.

Dedeke, Adenekan (2013), "A cognitive-intuitionist model of moral judgment", Journal of Business Ethics 126: 437-457.

Diccionario de la Lengua Española (2018), Cooperación. http://dle.rae.es/?id= Aiac8ws. Recuperado el 28 de diciembre de 2018.

(2018), Cooperar. http://dle.rae.es/?id=Aid2o2x. Recuperado el 28 de diciembre de 2018.

Friedman, James W. (1971), "A Non-cooperative Equilibrium for Supergames", Review of Economic Studies 38, 113 (197): 1-2.

Feenstra, Ramón A., Simon Tormey, Andreu Casero-Ripollés, and John Keane (2017), Refiguring Democracy: The Spanish Political Laboratory. New York: Routledge.

Frank, Robert H. (1988), Passions Within Reason: The Strategic Role of the Emotions. New York: W. W. Norton \& Company.

García-Marzá, Domingo (1992), Ética de la justicia: J. Habermas y la ética discursiva. Madrid: Tecnos.

(2004), Ética empresarial: del diálogo a la confianza. Madrid: Trotta.

(2005), La apuesta ética en las organizaciones sanitarias. Castellón de la Plana: Universitat Jaume I.

González-Esteban, Elsa (2001), La responsabilidad moral de la empresa. Una revisión de la teoría de Stakeholder desde la ética discursiva. Castellón de la Plana: Universitat Jaume I. 
ed. (2013), Ética y gobernanza: un cosmopolitismo para el siglo XXI. Granada: Comares.

Gould, Richard (1982), "To have and not to have: the ecology of sharing among huntergatherers". In Resource managers: North American and Australian huntergatherers, ed. Nancy M. Williams, and Eugene S. Hunn, 69-91. Boulder, CO: Westview Press.

Gutiérrez, Ingrid (2018), "Las ONGs en el punto de mira: campañas cada vez más agresivas para financiarse, La Información, 15 de febrero de 2018. https:// www.lainformacion.com/empresas/las-ongs-en-el-punto-de-mira-campanascada-vez-mas-agresivas-para-financiarse/6342204. Recuperado el 28 de diciembre de 2018.

Habermas, Jürgen (1981), Teoría de la Acción Comunicativa. Madrid: Taurus.

Hardin, Garrett (1968), “The Tragedy of the Commons”, Science 162 (1): 1243-1248.

Kahane, Guy and Nicholas Shackel (2010), Methodological issues in the neuroscience of moral judgement, Mind \& Language 25 (5): 561-582.

McCabe, Kevin, Daniel Houser, Lee Ryan, Vernon Smith, and Theodore Trouard (2001), "A functional imaging study of cooperation in two-person reciprocal exchange", Proceedings of the National Academy of Sciences of the United States of America 98 (20): 11832-11835.

Mediavilla, Daniel (2015), November 3. Michael Tomasello: "Para mejorar la sociedad no podemos obviar lo negativo de nuestra biología”. El País. https:// elpais.com/elpais/2015/10/20/ciencia/1445363532_639418.html

Olson, Mancur (1965), The Logic of Collective Action: Public Goods and the Theory of Groups. Harvard University Press: Harvard.

Ohtsuki, Hisashi, Yoh Iwasa, and Martin A. Nowak (2009), "Indirect reciprocity provides only a narrow margin of efficiency for costly punishment", Nature 457: 79-82.

Orlitzky, Marc (2016), "How cognitive neuroscience informs a subjectivistevolutionary explanation of business ethics". Journal of Business Ethics, Published online. https://doi.org/10.1007/ s10551-016-3132-8.

Ortega-Esquembre, César (2016), “¿Naturalizar la idea de justicia? Una respuesta crítica desde la teoría moral de Jürguen Habermas", Pensamiento 72: 827-848.

Ostrom, Elinor (1990), Governing the Commons. The Evolution of Institutions for Collective Action. Cambridge: Cambridge University Press.

(2000), El gobierno de los comunes. La evolución de las instituciones de acción colectiva. México, Fondo de Cultura Económica.

(2003), "Toward a Behavioral Theory Linking Trust, Reciprocity, and Reputation", Trust \& Reciprocity. Interdisciplinary Lessons from Experimental Research, ed. E. Ostrom, and James Walker, 19-79. New York: Russell Sage Foundation.

(2004). The Working Parts of Rules and How They May Evolve Over Time. 
Sahlins, Marshall (1972), Stone Age Economy. Chicago: Aldine. Atherton.

Schwartz, Mark S. (2016), "Ethical decision-making theory: An integrated approach", Journal of Business Ethics 139: 755-776. https://doi.org/10.1007/s10551-0152886-8.

Sennett, Richard (2003), Respect in a World of Inequality. New York: Penguin.

Smith, Adam (1776), An inquiry into the nature and causes of the wealth of nations. London: A. Strahan and T. Cadell.

Sturm, Rachel E. (2017), "Decreasing unethical decisions: The role of morality-based individual differences", Journal of Business Ethics 142: 37-57.

Sugden, Robert (1986), The Economics of Rights, Co-operation and Welfare. Oxford: Basil Blackwell.

Suzuki, S., K. Niki, S. Fujisaki y E. Akiyama (2011), "Neural basis of conditional cooperation". Social Cogniive \& Affective Neuroscience (3): 338-47.

Trivers, Robert L. (1971), “The evolution of reciprocal altruism”, Quarterly Review of Biology 46: 35-57.

Van den Bos, Wouter, Eric van Dijk, Michiel Westenberg, Serge A.R.B. Rombouts, and Eveline A. Crone (2009), "What motivates repayment? Neural correlates of reciprocity in the trust game", Social Cognitive Affective Neuroscience 4 (3): 294-304.

Woiceshyn, Jaana (2011), “A model for ethical decision making in business: Reasoning, intuition, and rational moral principles", Journal of Business Ethics 104: 311323. https://doi.org/10.1007/ s10551-011-0910-1.

Zamagni, Stefano (2006), Heterogeneidad motivacional y comportamiento económico. La perspectiva de la economía civil. Madrid: Unión Editorial.

(2009), "Fraternity, Gifts and Reciprocity in Cáritas in Veritate", Revista Cultural Económica 27 (75-76), 11-29. 


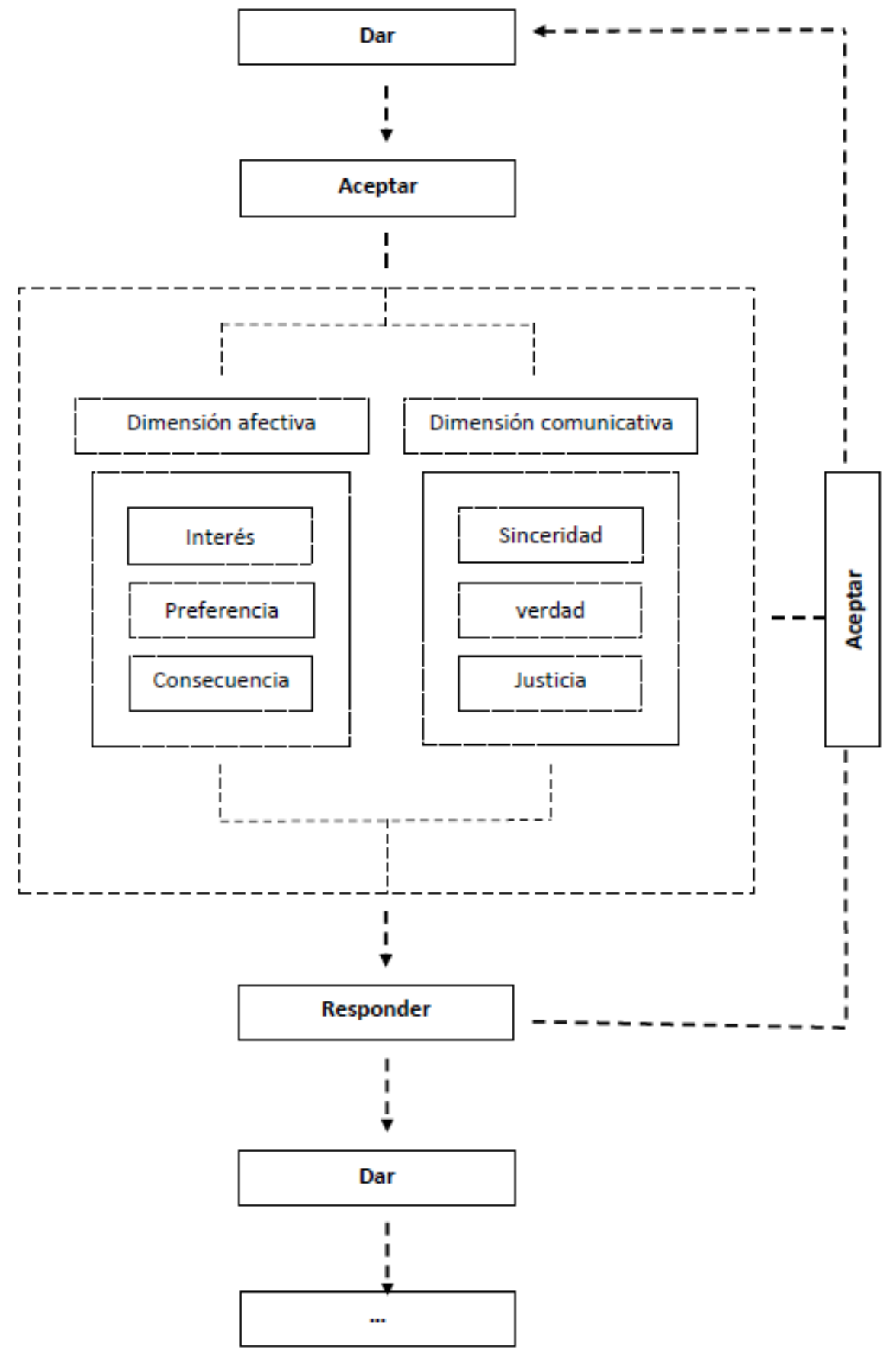

